\title{
Information Technology Service Quality Measurement: A Review
}

\author{
Vipul Jain ${ }^{1}$ and O. P. Wali ${ }^{2}$ \\ ${ }^{1}$ Ph.D. Student, ${ }^{2}$ Professor, Indian Institute of Foreign Trade, New Delhi, India \\ E-Mail: opwali@iift.edu,vipul_phd12@iift.edu
}

\begin{abstract}
This is a review of the current state of research in the area of Information Technology (IT) service quality measurement. The service quality research has many available theoretical models and corresponding measurement scales. There are ongoing debates and differing viewpoints in this area that have proliferated over more than thirty years, since the mid-1980s. This article attempts to identify the available instruments for IT service quality, and summarize the debate around them. Research on electronic services is examined additionally, since much of the academic community agrees on measuring them differently from human-mediated services. The study finds that SERVQUAL, despite its documented limitations, still provides an adequate and acceptable instrument for IT service quality measurement for researchers. The field of electronic services has a multitude of available valid scales to choose from, but not a single dominating scale or theory.

Keywords: Information Technology, Quality, Researchers
\end{abstract}

\section{INTRODUCTION}

As the nature of Information Technology (IT) function has shifted from a product and technology provider to a service provider, maintaining and managing service quality has assumed importance as one of the key objectives of IT managers, and has generated much research interest. Importance of service quality was recognized by including it as a third pillar in the very popular DeLone and McLean Information Systems success model (W H DeLone \& Mclean, 2003; William H. DeLone \& McLean, 1992), which seeks to provide an understanding of relationships between critical dimensions of success along which information systems are commonly evaluated. Much of the IT research in this area has been derived from the service quality research in the marketing discipline, which has traditionally defined service quality as a measured "gap" between expectations and perceptions of services (Parasuraman, Zeithaml, \& Berry, 1985).

It is important for both academicians and practitioners to understand the available models for measurement of IT service quality, and their suitability in the context the services are delivered and measured. There is debate in the academic community on theoretical approaches as well as measurement scales for service quality, and that debate has spilled over to the domain of Information Technology as well. This paper attempts to review and summarize the different points of view in the current state of research this area. This paper reviews the available published research on Measurement of IT service quality. The review has three broad objectives. First, we want to understand the prominent tenets and their overall evolution within the discipline of service quality, from a measurement perspective. Second, we want to understand how IT service quality research has evolved from it, and what are the different measurement scales available in the existing research that are specific to IT services. Finally, since electronic services (or E-services) are delivered differently from traditional human-mediated services, we seek to understand the available measurement scales and instruments in this area.

\section{METHOD AND SCOPE}

Forty-four papers are reviewed in this area, published between 1984 and 2017, out of which fourteen papers are in the service quality discipline, seventeen papers are in the IT service quality area, and thirteen papers deal with service quality of electronic services. The papers selected are only those which are published in reputed academic journals or conferences. Articles published in trade magazines, consulting reports or any non-peer reviewed publications are excluded.

In the existing literature, the term "Information Systems" quality or IS quality is often used commonly. This review ignores the minor semantic difference between the terms "Information Systems" and "Information Technology", as they both are used to describe the same technology and delivery system and uses only the term "IT service quality". The following sections discuss the findings from the review. First, we discuss the service quality measurement approaches.

\section{A. Service Quality}

The initial efforts to define and measure quality came from the goods or manufacturing sector, where quality was defined as "zero defects" or "conformance to requirements". These concepts, however, could not be applied to services, due to their unique characteristics of intangibility, heterogeneity, inseparability and perishability. Some of the early pioneering work in service quality came from marketing research by Parasuraman et al., [(Parasuraman et al., 1985)], who created the "gaps" model where service quality was defined as the difference between expected and perceived quality from the consumer's perspective. The gaps model is shown below where gaps 1 to 4 lead to gap 5, which is the suggested quality measure [Figure 1; Source(Parasuraman, 2004)]. 


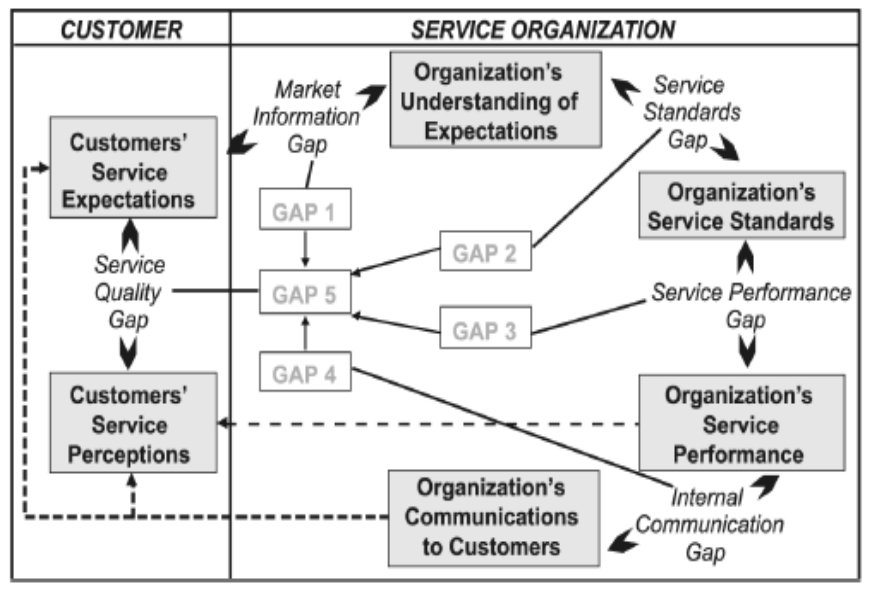

Fig. 1 Service Quality “Gap” Model

This "gaps" model ultimately led to the development of SERVQUAL instrument in 1988 by the same authors. It was initially proposed as a ten-dimension scale, which was later refined to five dimensions as below

1. Reliability: Ability to perform the promised service dependably and accurately.

2. Responsiveness: Willingness to help customers and provide prompt service.

3. Assurance: Knowledge and courtesy of employees and their ability to inspire trust and confidence.

4. Empathy: Caring, individualized attention the firm provides its customers.

5. Tangibles: Appearance of physical facilities, equipment, personnel, and communication materials

While SERVQUAL turned out to be a very popular instrument for service quality measurement in academic research, it has constantly been subject to many criticisms in the academic community. Cronin \& Taylor (Cronin \& Taylor, 1992) suggested that the SERVQUAL model was inadequate and examined it further. They advocated keeping the twenty-two items in the scale but measuring quality only as an attitude and perception in a SERVPERF scale. The effectiveness of the two scales was empirically examined for four different service industries and SERVPERF was found to be superior to SERVQUAL in explaining service quality variations in the sample data. The authors in another paper (Cronin \& Taylor, 1994) respond to the debate on SERVPERF and SERVQUAL and on measurement of quality as compared to customer satisfaction. They suggest a restriction of quality measurement to long-term attitudes and measurement of customer satisfaction to transactionspecific judgements.

In a review of the preceding fifteen years of research, Ladhari (Ladhari, 2008) looked at thirty industry-specific scales of service quality measurement, and concluded that while SERVQUAL is widely criticized, it continues to be the most useful model for measuring service quality. None of the alternative scales have adopted the methodological rigour of Parasuraman et al., in development and refinement of the scale. In another study, Ladhari (Ladhari, 2009) tries to summarize the SERVQUAL debate. The identified key points from the study are theoretical issues with the gap model, validity and reliability of the scale, emphasis on process as opposed to outcome, cultural context that introduces bias in scale, non-applicability to e-services, need for industry-specific scales and hierarchical constructs, and, finally, the use of reflective scales as opposed to formative scales. Conger et al., (Conger, Hefley, Galup, \& Dattero, 2013) review service quality research in the disciplines of marketing, IT and supply chain to explore common themes, issues and develop an agenda for future work. They find that while SERVQUAL has been extensively used in more than 1000 studies, and there is evidence that it does differentiate something, there is no verification in any study that services designated as poor or excellent using SERVQUAL measurement are indeed so. They infer that "... the research relies on statistics to tell the story without validating the story".

SERVQUAL has been adapted and modified into many variations, and there continue to be differences on the best approach to use the model most effectively. There is a view that performance-only scale has better predictive validity than the gap scores. This has been termed as SERVPERF in its many variations (Ladhari, 2008). There is also some research that all dimensions of SERVQUAL may not matter equally to the consumers. Landrum et al., (Landrum, R. Prybutok, Zhang, \& A. Peak, 2009) find that there is some evidence that service quality dimensions can be distinguished between "nice to have" i.e. softer aspects of tangibility, empathy and assurance; and "essential" dimensions of responsiveness and reliability, which can be more objectively measured. In high-pressure situations, the objective or essential dimensions are more valued by the users.

Seth et al., reviewed nineteen conceptual service quality models reported between 1984 and 2003 (Seth, Deshmukh, \& Vrat, 2005). They infer that there is neither a wellaccepted conceptual definition of service quality, nor is there a commonly accepted operational definition of its measurement. Majority of models reviewed, however, support evaluation by comparing service quality expectations with the actual quality experienced. While there is a widespread support for gap model and SERVQUAL, there is much debate on its actual dimensions, and also the desirability of measuring SERVPERF versus SERVQUAL. They also map the nineteen models reviewed against an eleven-item framework created by them for suitability of the quality measurement model and infer that none of the reviewed models caters to all the factors.

Dabholkar et al., (Dabholkar, Shepherd, \& Thorpe, 2000) advocate a direct measure of service quality versus a computed measure through multiple dimensions. They argue that the dimensions of service quality in the disconfirmation paradigm are better understood as the antecedents of quality. In their empirical study, they 
compare perception-based measurement with gaps measurement and conclude that the former provides a superior method for service quality measurement. Also, they find that a cross-sectional quality measurement is superior to a longitudinal measurement, where the time lag between expectation and actual service performance perception is taken into account in the measurement design.

Brady and Cronin (Brady \& Cronin, 2001) propose a "unifying" third-order hierarchical structure and empirically examine it for validity. The first order dimensions are interaction quality, physical environment quality, and outcome quality.A heavily debated dimension in service quality research is the distinction between functional [or service delivery or process or "how"] quality and technical [or outcome or intrinsic or "what"] quality. It is also referred to as the debate between "marketing" definition of quality and "Nordic" definition of quality. Functional quality pertains to the experience of the consumer during service delivery, and technical quality refers to the actual outcome delivered, which in many cases is experienced post the service delivery. There is a significant stream of opinion that technical quality measurement is important, and that gaps approach to quality measurement ignores it. Most scales used in applied research, however, continue to use functional quality. A 15-year review of 30 different service quality scales (Ladhari, 2008) revealed that the technical dimension of quality was used in very few studies.

Kang \& Jeffrey (Kang \& James, 2004) empirically examine and compare Gronroos' model with SERVQUAL and conclude that the former is a more appropriate representation of service quality as the latter focuses only on the functional quality dimensions.

Kang et al., (Kang, 2006) propose a hierarchical measurement model that integrates technical and functional quality dimensions. The model was tested empirically for Korean cell phone users through 464 survey responses. Technical service quality scale was developed through user interviews. Functional service quality was measured through SERVQUAL. The results confirmed a multidimensional hierarchical structure for functional service quality.

Walker et al., (Walker, Johnson, Leonard, \& Walker, 2006) discuss the concept of customer value determined by both intrinsic [functional] quality and extrinsic [technical] quality, and make a case that unless both are taken into account, the theoretical modeling will be incomplete. They examine the service-profit chain developed and modeled by Sasser et al. (Sasser, Schlesinger, \& Heskett, 1997), where the customer's sense of value is an equation calculated with reference to the perceived quality of results received and the perceived quality of how these have been delivered, balanced against the aggregated costs of availing the service. Service quality is an extrinsically perceived attribution based on the customer's experience in and through the service encounter. Authors propose a modified service-profit model to account for intrinsic value, as depicted below [

Fig; Source - (Walker et al., 2006)]

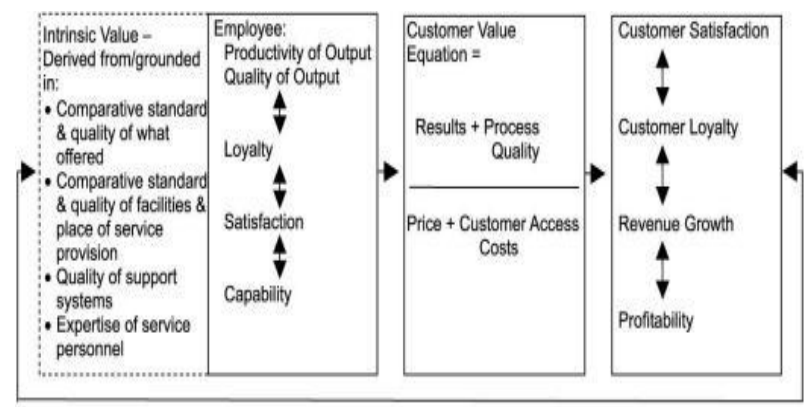

Source: Heskett et al. (1997, p.12)

Fig. 2 Modified Service-Profit Model

Gronroos (Grönroos, 2001) reviews the service quality debate and questions the relevance of the quality debate. He suggests measurement of customer satisfaction as in indicator of how well a service has served the customer. The technical and functional dimensions of service quality are similar to product features in case of physical products and opines that in retrospect, maybe the "service quality" dimensions should have been termed as "service features", and that may have avoided the debate altogether.In the next section, we discuss the IT service quality approaches.

\section{B. IT Service Quality}

Within the field of information systems, as IT organizations have evolved from software and systems providers to service providers, the importance of service quality is getting recognized in academic research. Recognizing the role of service quality, DeLone and McLean (W H DeLone \& Mclean, 2003) modified their Information Systems (IS) success model and added service quality as a third component of IS success, in addition to system quality and information quality. The DeLone and McLean model has been extensively used in academic research, and empirically tested. The authors, in a ten-year review of the model in 2003 , found 285 studies that had referred to it, and sixteen studies that had empirically proved thirty-six of the thirtyeight success factor associations in the model. The updated model is reproduced in Fig [Source - DeLone \& McLean, 2003].

Service quality also impacts the trust, commitment and intention on the part of IT users to consume IT services. Park et al., (Park, Lee, Jang, \& Lee, 2013) in an empirical study find that both technical and functional service quality positively impact affective and cognitive user trust. In this study, they observe that impact of functional service quality on trust is higher than that of technical service quality. Putting this updated model to empirical test, Pitt et al., (Pitt, 
Watson, \& Kavan, 1995) assessed suitability of SERVQUAL in three different types of organizations in three countries. After examination of content validity, reliability, convergent validity, nomological validity, and discriminant validity, the study concludes that SERVQUAL is an appropriate instrument for researchers seeking a measure of IS service quality. The study also identifies exploration of the effects of managerial actions on service quality as an area of future research.

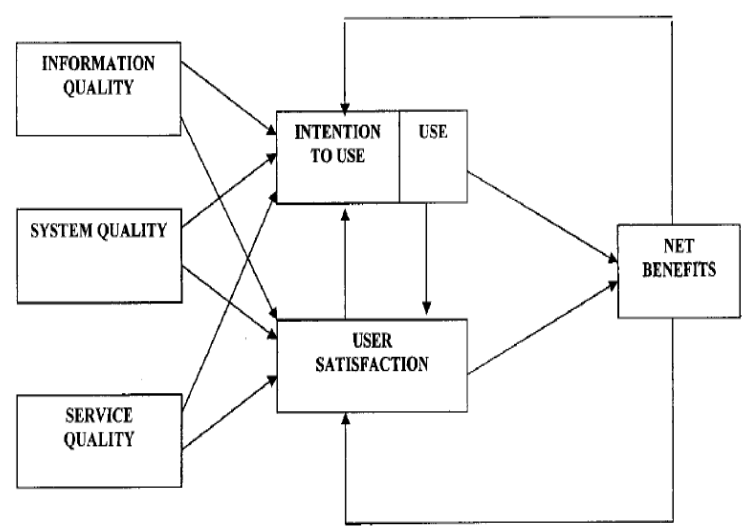

Fig. 3 IS Success Model

Service Quality is also closely linked to user or customer satisfaction and many studies have explored this relationship. Kettinger and Lee (W. Kettinger \& Lee, 1994) studied the relationship between user satisfaction with IS services and the SERVQUAL dimensions of quality, found two dimensions of service quality - reliability and empathy - to be significant predictors of user satisfaction. They suggested quality to be an antecedent of satisfaction, but the causality of the relationship required further longitudinal studies.

SERVQUAL and its variants continue to dominate the IT service quality measurement in literature. Many researchers have adapted SERVQUAL and modified dimensions and measures to fit the IT context. A modified scale of SERVQUAL for IT - IT SERVQUAL - was created by Kettinger and Lee (W. Kettinger \& Lee, 1994). Chang et al., (CHANG \& KING, 2005), while creating a performance instrument for IT by building upon the DeLone and McLean success model, use SERVQUAL for measuring the service quality dimension. Kettinger \& Lee (W. J. Kettinger \& Lee, 2005) propose a modified scale adapted from SERVQUAL, that was based on the concept of "zones of tolerance" to measure expectations. They suggested that customers have a desired service level, and an adequate service level expectation, and between these two levels is a "zone of tolerance" that customers find an acceptable level of service. Miller et al., (Miller, Hardgrave, \& Jones, 2013) proposed an ISS-QUAL scale for the services delivered by the IS function to overcome some shortcomings of SERVQUAL. This was a three-dimensional scale based on the three factors of service delivery, service product, and the service environment. The service delivery dimension is adapted from the original SERVQUAL items. This proposed scale is compared with SEVQUAL in an empirical test and found to have better explanatory power. This scale was further tested in the context of public sector in another study and found to exhibit adequate levels of validity (Marchiori, Mainardes, \& Rodrigues, 2017). Cronholm et al., (Cronholm \& Salomonson, 2014)] attempt to adapt SERVQUAL to ITSM by adding a category attribute from the original 10-dimension instrument. Hochstein (Hochstein, Zarnekow, \& Brenner, 2004) proposes a modified SERVQUAL to measure service quality at the individual service level, while most studies till then had done this at the IT functional level.

The debate over SERVQUAL instrument continues in the IT services research as well. Chang et al., (CHANG \& KING, 2005), note that "the controversy over SERVQUAL in marketing has carried over into IS, suggesting that more research needs to be conducted to measure IS service quality." Tate et al., (Tate \& Evermann, 2010) say that SERVQUAL gaps model is without a theoretical basis- "it is a dependent variable without a theory or known predictors."

Another criticism leveled against the current IT research on service quality, especially SERVQUAL-based research is that it is not building up a research tradition in spite of volumes of research. In a study of 57 articles published between 1985 to 2006, that use SERVQUAL, Tate et al., (Sylvester, Tate, \& Johnstone, 2007) find that research is simply piling up, instead of building a coherent body of work. They apply Soft Systems Method [SSM] to understand why SERVQUAL still continues to be popular, despite its continued criticisms. They find that SERVQUAL has flawed theoretical basis, and questionable predictive ability, but its usefulness lies in the fact that researchers can confidently carry out legitimate studies using this instrument, with broad acceptance in the academic community. In other words, its usefulness lies in its popularity.

In spite of the criticisms, there is a broad acceptance of the usefulness of SERVQUAL, though. In a review of the state of research of service quality measurement, three research strains - marketing, supply chain and IT - were examined (Conger et al., 2013). The study finds that the cumulative research is limited, and as research proliferates, it becomes of increasingly limited value. Most IT research is found to be in the area of website service quality. Authors say that "none of the studies provide the depth or breadth of instrument validation or testing of SERVQUAL and none are shown to be superior. Also, though many of these use SERVQUAL as starting point, they mostly ignore prior work, appearing to reinvent the wheel of service measurement but without the rigor of the many predecessor studies." The study proposes further research on how the use of frameworks for developing services (e.g., ITIL) relates to service quality. 
We can summarize the SERVQUAL debate in three propositions. First, despite criticisms and shortcomings, SERVQUAL is an acceptable instrument for measuring service quality within IS research community. This means it can be deployed for measurement for research outcomes, that are likely to be deemed acceptable by the scientific community. Second, the theoretical basis and validity of SERVQUAL scale has been often questioned. There are valid criticisms of the scale, that need to be addressed eventually for it to be a true measure of service quality. Third, while many researchers have tried to propose alternatives to SERVQUAL with varying levels of success, none has been conclusively proven to be superior. In fact, many of the proposed scales are adaptations of the "gap" model on which SERVQUAL is based.

The research for developing better IT quality frameworks is a continuing effort. In a series of 3 studies, Lepmets et al., [(Lepmets, Cater-Steel, Gacenga, \& Ras, 2012); (Lepmets, Mesquida, Cater-Steel, Mas, \& Ras, 2014); (Lepmets, Ras, \& Renault, 2011)] attempt to create a comprehensive IT service quality measurement framework, with elements drawn from the existing body of knowledge in software engineering and IT service domains: Practical Software and Systems Measurement (PSM), Software product Quality Requirement and Evaluation, SQuaRE (ISO/IEC 25010 2009), ITIL, SERVQUAL and ITSM - Process Reference Model (ISO/IEC 20000-4 2010). After three iterations, there are thirty-six measures in twenty-five measurement categories in their model.

Miller et al., (Miller et al., 2013) propose a scale for Information Systems service quality measurement called ISS-QUAL. This measures performance and expectation gap across three dimensions of service delivery, service product and service environment. A comparison with SERVQUAL was made in an empirical study across twenty organizations with 209 survey respondents. The results showed that ISS-QUAL explained $19 \%$ more variance in service quality as compared to SERVQUAL. It is also parsimonious with only sixteen indicators as compared to SERVQUAL's forty-four. The model was further tested empirically by Marchiori et al., (Marchiori et al., 2017) in a survey of 927 users across Brazilian public service organizations. After removal of an indicator, they found the instrument demonstrated adequate construct validity. Next, we review the approaches for measurement of electronic service quality.

\section{Online Services or E-Services Quality}

There is a general agreement in literature that services delivered through digital or electronic means [e-services] need a different approach for quality measurement due to the reduced human intervention and contact, as opposed to traditional services.

Parasuraman, among the creators of SERVQUAL, proposed a different gaps model for e-services (Parasuraman, 2004) and agreed that mere adaptation of SERVQUAL scale is inadequate to measure online or e-service quality [for websites]. A new scale called E-S-QUAL was developed, consisting of twenty-two items in four dimensions (Parasuraman, Zeithaml, \& Malhotra, 2005). The scale's reliability and validity were tested empirically and were found to be positive. The dimensions of the proposed scale are

1. Efficiency: The ease and speed of accessing and using the site.

2. Fulfillment: The extent to which the site's promises about order delivery and item availability are fulfilled.

3. System Availability: The correct technical functioning of the site.

4. Privacy: The degree to which the site is safe and protects customer information.

Santos (Santos, 2003) proposes an e-service quality model based on focus group discussions. The proposed model has an incubative dimension (design aspects) and an active dimension (performance aspects) and each dimension has five to six determinants. The model needs scale development and empirical validation.

Yang et al., (Yang, Cai, Zhou, \& Zhou, 2005) developed and validated an instrument to measure user perceived service quality of web portals. They proposed and validated a five-dimension service quality instrument involving: usability, usefulness of content, adequacy of information, accessibility, and interaction.

Collier et al., (Collier \& Bienstock, 2006) extended to extend the work on e-service quality and proposed and tested a conceptual framework that combines process, outcome, and recovery dimensions in a formative scale. ES-QUAL was adapted for enterprise intranet services by Barnes \& Vidgen (Barnes \& Vidgen, 2012), who developed a model for intranet quality and acceptance. They based this scale on a previously developed scale called eQual (Barnes S, 2002) which had five quality dimensions of usability, design, information, trust, and empathy. Empathy and trust were not expected to be relevant in corporate settings, and therefore the three dimensions of usability, design and information quality were retained in the proposed scale, which was called iQual. The scaled was tested for reliability and validity.

There is a significant body of research, that finds SERVQUAL inappropriate for online or e-services research. Tate et al., (Tate \& Evermann, 2010) suggest some additional reasons for SERVQUAL inappropriateness for online services - gaps model was developed for face to face environment and is not applicable to online services; the construct itself is incorrectly specified as multiple reflective dimensions of a single latent variable; and IS research is not cumulative and is not leading to a convergence. Rather, research is just building up in volume. Most researchers form their own derivative scales from SERVQUAL by modifying some of its dimensions and perform limited 
validity testing. Therefore, objective literature reviews are very difficult to conduct.

In a literature review of twenty-seven papers on e-service quality, Ladhari (Ladhari, 2010) finds that the convergent, discriminant and predictive or nomological validity - of most of the scales are not examined. He finds that while there is no consensus on the dimensions, six dimensions recur more consistently than others - reliability/ fulfillment; responsiveness; ease of use/usability; privacy/security, web design; and information quality/content. He finds that most scales ignore technical service quality and identifies this as an area of further research.

Supporting the view that traditional quality definitions and measurements are not applicable to digital services, Tate $e t$ al., (Tate, Furtmueller, Gao, \& Gable, 2014) identify many unique characteristics of digital services that demand a different approach to quality measurement - Customer has a role in co-creation of digital service quality; cognitive dissonance i.e. with time, for frequently consumed services, the gap between future expectations and past experience tends to close; role of a user learning curve to achieve optimal effectiveness; and in case of services when customer agrees in advance to comply, the notion of an expectation and perception gap is invalid. The authors recommend looking at the overall value lifecycle of service consumption - from contact to recovery in the event of a failure. This is similar to how value creation is looked at in the value chain models.

As online or electronic channels evolve, specialized scales for specific industries, technologies or applications continue to be proposed and tested. Huang et al., (Huang, Lin, \& Fan, 2015) propose, test and refine an instrument for service quality measurement in mobile environments. They propose two distinct scales derived from SERVQUAL, called mobile-SERVQUAL or M-S-QUAL. For virtual products shopping, a five-dimension sixteen-indicator scale is proposed, and for physical products shopping, a fourdimension fifteen-indicator scale is proposed. Recognizing that existing service quality models have limited applicability in the cloud environment, Zheng et al., (Xianrong Zheng, Martin, Brohman, \& Li Da Xu, 2014) attempt to create a model that is objective, computable, and verifiable, so that providers can gauge the Quality of Service $[\mathrm{QoS}]$ delivered, and consumers can validate the QoS received. The authors contend that SERVQUAL and its derivative models for e-services cannot be applied to cloud services because of their subjective dimensions. They propose a six-dimension model with calculations for the metrics as well. The measure is validated with an empirical study of three leading cloud service providers. Wang et al., (Wang, Yeh, Yen, \& Nugroho, 2016) investigate the sequential influence of e-service quality on in-person service quality in a hybrid service format in which interpersonal and computer mediated services coexist but at different points in time. Their empirical study shows that eservice quality directly and positively affects in-person service quality. They also find that in-person service quality fully mediates the effects of e-service quality on perceived value and customer satisfaction. The sample of 233 responses was collected from users in the airline industry, where hybrid service encounters are common.

Yaya et al., (Petnji Yaya, Marimon, \& Casadesús, 2017) selected twenty-one papers that have previously used the ES-QUAL scale, and invited their authors to share their experiences in using the scale through a Delphi study. There was a consensus that the 'fulfilment' dimension is significant only for those websites that sell and deliver physical goods. There was also agreement that the "efficiency" dimension should be updated because of advancements in the state of information and communication technologies since the scale was initially proposed. The experts also agreed that the dimensionality problems in many cases could be attributed not only to the specific industry setting, but also to the methodology used for analysis.

From the review, we can conclude that a) E-service Quality cannot be adequately measured using SERVQUAL; and b) Effective scales for e-service quality measurement are context-specific, and no universal scale has been designed or proposed that can apply to all cases.

\section{DISCUSSION}

From the reviewed literature, it can be inferred there is no universally acceptable theoretical models or scales for service quality measurement. In fact, there is fundamental debate on whether the "dimensions" of quality are actually its antecedents. Being a latent variable, no scale is likely to be a perfect measure of the variable, but the theoretical underpinnings of most of these scales are questionable as well.

For the purpose of conducting meaningful studies on quality, however, SERVQUAL provides an adequate instrument to the researchers, which has been amply used and has demonstrated acceptable levels of validity in prior studies. While its theoretical groundings are challenged, it is widely acceptable that the latent variable it measures, does correlate significantly with service quality.

For electronic services, scales are different, and there is a wide agreement on the need to have different scales for different types of delivered services. There is not one scale that dominates (like SERVQUAL does as a general measure), but there are many scales which have been tested and have demonstrated adequate validity for different electronic services for researchers to choose from.

Some gaps in the existing service quality research are also identified. First, service quality research is mainly dominated by measurement, but very limited research is done on the antecedents of service quality. Better understanding of antecedents can be useful aid in identifying and recovering from quality problems. Second, 
technical quality measurement scales are rare in IT services research, which is dominated by SERVQUAL measurement. Many authors acknowledge the importance of technical service quality measurement, but few established scales are available for the same. Third, given the proliferation of innovative automated IT services delivered through hitherto unavailable channels like mobiles and cloud, there is a need to relook at the conceptualization of service quality for e-services. Most of current scales were developed in the context of electronic commerce in the early 21 st century, whereas many of these newer services do not involve commercial transactions, e.g. social media services. It may be possible to design objective scales for quality in these case, given the lack of human element in the delivery, and future researchers working in the area of IT service quality can explore it further.

\section{REFERENCES}

[1] Barnes, S. J., \& Vidgen, R. (2012). User acceptance and corporate intranet quality: An evaluation with iQual. Information and Management, $\quad 49(3-4), \quad$ 164-170. https://doi.org/10.1016/j.im. 2012.02.002.

[2] Barnes S, V. (2002). An integrative approach to the assessment of ecommerce quality. Journal of Electronic Commerce Rese.arch, 3(2), 114-127. https://doi.org/10.1080/00223891.2013.770400

[3] Brady, M. K., \& Cronin, J. J. (2001). Some New Thoughts on Conceptualizing Perceived Service Quality: A Hierarchical Approach. Journal of Marketing, 65(3), 34-49. https://doi.org/ 10.15 09/jmkg.65.3.34.18334.

[4] CHANG, J. C.-J., \& KING, W. R. (2005). Measuring the Performance of Information Systems: A Functional Scorecard. Journal of Management Information Systems, 22(1), 85-115. https://doi.org/10.1080/07421222.2003. 11045833.

[5] Collier, J. E., \& Bienstock, C. C. (2006). Measuring service quality in E-retailing. Journal of Service Research, 8(3), 260-275. https://doi.org/10.1177/1094670505278867.

[6] Conger, S., Hefley, W. E., Galup, S., \& Dattero, R. (2013). Service Quality Measurement: Past and Future Service Quality Measurement : Past and Future. All Sprouts Content, 521. Retrieved from http://aisel.aisnet.org/sprouts_all/521.

[7] Cronholm, S., \& Salomonson, N. (2014). Measures that matters: Service quality in IT service management. International Journal of Quality and Service Sciences, 6(1), 60-76. https://doi.org/10.1108/ IJQSS-12-2012-0022.

[8] Cronin, J. J., \& Taylor, S. a. (1992). Measuring Service Quality: A Reexamination and Extension. Journal of Marketing, 56(3), 55. https://doi.org/10.2307/1252296.

[9] Cronin, J. J., \& Taylor, S. a. (1994). SERVPERF versus SERVQUAL: and Reconciling of Service Measurement Perceptions Quality. Journal of Marketing, 58(1), 125-131. https://doi.org/10. 2307/1252256.

[10] Dabholkar, P. A., Shepherd, C. D., \& Thorpe, D. I. (2000). A comprehensive framework for service quality: An investigation of critical conceptual and measurement issues through a longitudinal study. Journal of Retailing, 76(2), 139-173. https://doi.org/10.10 16/s0022-4359(00)00029-4.

[11] DeLone, W. H., \& Mclean, E. R. (2003). The DeLone and McLean Model of Information Systems Success: A Ten-Year Update. Journal of Management Information Systems / Spring, 19(4), 9-30. https:// doi.org/10.1073/pnas.0914199107.

[12] DeLone, W. H., \& McLean, E. R. (1992). Information Systems Success: The Quest for the Dependent Variable. Information Systems Research, 3(1), 60-95. https://doi.org/10.1287/isre.3.1.60.

[13] Grönroos, C. (2001). The perceived service quality concept - a mistake? Managing Service Quality: An International Journal, 11(3), 150-152. https://doi.org/10.1108/0960452011 0393386.

[14] Hochstein, A., Zarnekow, R., \& Brenner, W. (2004). Managing IT service quality as perceived by the customer: The service oriented IT
Servqual. Proceedings of the International Telecommunications Society (ITS) 15th Biennial Conference, 1-7. Retrieved from http://itseurope.org/ITS CONF/berlin04/Papers/Hochstein_paper.pdf.

[15] Huang, E. Y., Lin, S. W., \& Fan, Y. C. (2015). M-S-QUAL: Mobile service quality measurement. Electronic Commerce Research and Applications, 14(2), 126-142. https://doi.org/10.1016/j. elerap.2015. 01.003 .

[16] Kang, G. (2006). The hierarchical structure of service quality: integration of technical and functional quality. Managing Service Quality: An International Journal, 16(1), 37-50. https://doi.org/ 10.1108/09604520610639955.

[17] Kang, G., \& James, J. (2004). Service quality dimensions: an examination of Grönroos's service quality model. Managing Service Quality: An International Journal, 14(4), 266-277. https://doi.org/10. 1108/09604520410546806.

[18] Kettinger, W. J., \& Lee, C. C. (2005). Zones of tolerance: Alternative scales for measuring information systems service quality. MIS Quarterly: Management Information Systems, 29(4), 607-623. Retrieved from https://www.scopus.com/inward/record.uri?eid=2s2.0-33645141935\&partnerID=40\&md5=bbf56f788361 c6858071 c2ffb4547d61.

[19] Kettinger, W., \& Lee, C. (1994). Perceived Service Quality and User Satisfaction with the Information Services Function*. Decision Sciences, 25(5-6), 737-766. https://doi. org/10.1111/j.1540-5915. 1994.tb00829.x.

[20] Ladhari, R. (2008). Alternative measures of service quality: A review. Managing Service Quality, 18(1), 65-86. https://doi.org/10.1108/ 09604520810842849.

[21] Ladhari, R. (2009). A review of twenty years of SERVQUAL research. International Journal of Quality and Service Sciences, 1(2), 172-198. https://doi.org/10.1108/1756 6690910971445.

[22] Ladhari, R. (2010). Developing e-service quality scales: A literature review. Journal of Retailing and Consumer Services, 17(6), 464-477. https://doi.org/10.1016/j.jretconser. 2010.06.003.

[23] Landrum, H., R. Prybutok, V., Zhang, X., \& A. Peak, D. (2009), Measuring IS System Service Quality with SERVQUAL: Users' Perceptions of Relative Importance of the Five SERVPERF Dimensions. Informing Science: The International Journal of an Emerging Transdiscipline, 12(3), 017-035. https://doi.org/10.289 $45 / 426$.

[24] Lepmets, M., Cater-Steel, A., Gacenga, F., \& Ras, E. (2012). Extending the IT service quality measurement framework through a systematic literature review. Journal of Service Science Research, 4(1), 7-47. https://doi.org/10.1007/s12927-012-0001-6.

[25] Lepmets, M., Mesquida, A. L., Cater-Steel, A., Mas, A., \& Ras, E. (2014). The evaluation of the IT service quality measurement framework in industry. Global Journal of Flexible Systems Management, 15(1), 39-57. https://doi.org/10.1007/s40171-0130052-7.

[26] Lepmets, M., Ras, E., \& Renault, A. (2011). A Quality Measurement Framework for IT Services. 2011 Annual SRII Global Conference, 767-774. https://doi.org/10.1109/SRII. 2011.84.

[27] Marchiori, D. M., Mainardes, E. W., \& Rodrigues, R. G. (2017). Validation of the ISS-QUAL and the role of gender, age and education on it service quality in the public sector. Information Technology and Management, 1-14. https://doi.org/10.1007/s10799017-0281-0.

[28] Miller, R. E., Hardgrave, B. C., \& Jones, T. W. (2013). ISS-QUAL: A Measure of Service Quality for the Information Systems Function. Information Systems Management, 30(3), 250-262. https://doi.org/ 10.1080/10580530.2013.794633.

[29] Parasuraman, A. (2004). Assessing and improving service performancefor maximum impact: Insights from a two-decade-long research journey. Performance Measurement and Metrics, 5(2), 4552. https://doi.org/10.1108/1467804041 0546064

[30] Parasuraman, A., Zeithaml, V. A., \& Berry, L. L. (1985). A Conceptual Model of Service Quality and Its Implications for Future Research. Journal of Marketing. https://doi.org/10. 2307/1251430.

[31] Parasuraman, A., Zeithaml, V. A., \& Malhotra, A. (2005). E-SQUAL a multiple-item scale for assessing electronic service quality. Journal of Service Research, 7(3), 213-233. https://doi.org/ 10.11 77/1094670504271156.

[32] Park, J., Lee, H., Jang, J., \& Lee, J. (2013). Roles of Technical and Functional Service Quality, and Cognitive and Affective Trust in IT 
Service Encounter. Journal of Next Generation Information Technology, 4(8), 312-321.

[33] Petnji Yaya, L. H., Marimon, F., \& Casadesús, M. (2017). The expert experience in adopting the E-S-QUAL scale. Total Quality Management and Business Excellence, 28(11-12), 1307-1321. https://doi.org/10.1080/14783363.2015.1135728.

[34] Pitt, L. F., Watson, R. T., \& Kavan, B. C. (1995). Service Quality: A Measure of Information Systems Effectiveness. MIS Quarterly, 19(2), 173-187.

[35] Santos, J. (2003). E-service quality: A model of virtual service quality dimensions. Managing Service Quality: An International Journal, 13(3), 233-246. https://doi.org/10.1108/09604520310476490.

[36] Sasser, W. E., Schlesinger, L. A., \& Heskett, J. L. (1997). Service Profit Chain. Free Press. Retrieved from https://books.google.co.in/ books?hl=en\&lr=\&id=f8PpwCgtp9MC\&oi=fnd\&pg=PT18\&dq=hesk ett+service+profit+chain\&ots $=\mathrm{PP} 5 \mathrm{qCOjxmb} \&$ sig $=\mathrm{NTePCi} 7 \mathrm{~b} 7 \mathrm{ukQoz}$ $\mathrm{mjtQH} 4 \mathrm{gD} 8 \mathrm{beaY} \mathrm{v}=$ onepage $\& \mathrm{q}=$ heskett service profit chain\& $\mathrm{f}=$ false.

[37] Seth, N., Deshmukh, S. G., \& Vrat, P. (2005). Service quality models: a review. International Journal of Quality \& Reliability Management, 22(9), 913-949. https://doi.org/10.1108/02656710510625211

[38] Sylvester, A., Tate, M., \& Johnstone, D. (2007). Re-presenting the Literature Review: A Rich Picture of Service Quality Research in Information Systems. In PACIS 2007 Proceedings, 113

[39] Tate, M., \& Evermann, J. (2010). The End of ServQual in Online
Services Research: Where to from here? E-Service Journal, 7(1), 6085. https://doi.org/10.2979/ESJ.2010.7.1.60.

[40] Tate, M., Furtmueller, E., Gao, H., \& Gable, G. G. (2014). RECONCEPTUALIZING DIGITAL SERVICE QUALITY: A CALL-TO-ACTION AND RESEARCH APPROACH. In PACIS 2014 proceedings, 11. Retrieved from http://aisel.aisnet. org/pacis 2014/11.

[41] Walker, R. H., Johnson, L. W., Leonard, S., \& Walker, R. H. (2006). Re-thinking the conceptualization of customer value and service quality within the service-profit chain. Managing Service Quality: An International Journal, 16(1), 23-36. https://doi.org/10.1108/0 9604520610639946

[42] Wang, T., Yeh, R. K. J., Yen, D. C., \& Nugroho, C. A. (2016) Electronic and in-person service quality of hybrid services. Service Industries Journal, 36(13-14), 638-657. https://doi.org/10.1080/02 642069.2016.1272590.

[43] Xianrong Zheng, Martin, P., Brohman, K., \& Li Da Xu. (2014). CLOUDQUAL: A Quality Model for Cloud Services. IEEE Transactions on Industrial Informatics, 10(2), 1527-1536. https://doi. org/10.1109/TII.2014.2306329.

[44] Yang, Z., Cai, S., Zhou, Z., \& Zhou, N. (2005). Development and validation of an instrument to measure user perceived service quality of information presenting Web portals. Information \& Management, 42(4), 575-589. https://doi.org/10.1016/j.im.2004.03.001. 